Military Technical College

Kobry Elkobbah,

Cairo, Egypt

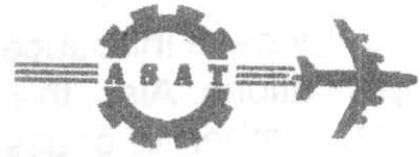

$8^{\text {th }}$ International Conference on Aerospace Sciences \& Aviation Technology

\title{
DESIGN OF A FAULT TOLERANT SWITCHED RELUCTANCE MOTOR FOR AN AIRCRAFT FUEL PUMP APPLICATION
}

Amged S. El-wakeel* , Said A. Gawish"k, M. A. L. Badr"k*k

\section{ABSTRACT}

In military field, harsh environment, and aerospace applications, a fault must not lead to another fault or to the loss of any features of the system. The system must be automatically re-configurable i.e. it must be fault tolerant system.

Switched Reluctance Motor (SRM) drives are gaining increasing interest mainly due to the simple technology involved in its manufacture, with low cost and high reliability. Also, SRMs have been researched for safety critical applications, due to their inherent fault tolerance characteristics.

This paper focuses on the engineering design and simulation of a $16 \mathrm{KW}, 270 \mathrm{~V}$ DC, $13000 \mathrm{rpm}$ SRM which can be used as an aircraft fuel pump. This paper explains the principal electromagnetic motor and drive faults and their critical operating conditions. The design approach and the motor design parameters are discussed briefly to explain the design methodology. Finally, a combination of simulation results and design motor dimensions is provided to verify the required motor performance.

\section{KEYWORDS}

Electric Machines, Switched Reluctance Motor and Fault Tolerant Drives.

\section{INTRODUCTION}

In military applications, a whole failure of the drive has a severe impact on the operation of a system and on the human safety. In such applications, a single point fault must not lead to another fault or to the loss of any features of the system. The system must be capable of continuing its operation satisfactory i.e. it must be a fault tolerant system. Many authors claim:t that the SRM drives are inherently fault tolerant drives [1].

*h* Professor, Dept. Of Elect. Power \& Machines, Faculty of engineering, Ain Shams University, Cairo, Egypt.** Associate professor, Dept. Of Elect. Power \& Energy, Military Technical College. * M. Sc. , Dept. Of Elect. Power \& Energy,
Military Technical College. 
In previous work [2], the authors have introduced the concept of a fault tolerant SRM drive for safety critical applications. Also, the authors had discussed some of design considerations such as number of phases, stator shape and others from the fault tolerance point of view. It was concluded that the SRMs have a degree of fault tolerance not found in other motor drives [2].

This work presents the key design of a $16 \mathrm{KW}, 270 \mathrm{~V}, 13000 \mathrm{rpm}$ SRM drive which can be used in aerospace applications.

\section{UPNORMAL AND FAU'LT CONDITIONS}

The principal electrornagnetic faults which may occur within the machine and its drive are: winding open circuit, partial winding short circuit, complete winding short circuit, switching device open circuit and switching device short circuit [3] . The critical operestion conditions include the operations at high temperature, the operation at verry high-speed conditions, the operation at dusty and dirty conditions and the operation at wet condition [2].

In general, the designer must face the general design limitations in choosing the suitable amcunt, shape and type of materials for the fabrication of the required machine parts. These limitations include the consumer's requirements, the saturation level, the allowed temperature rise, the value of power factor, the efficiency and mechanical design limitations. For safety critical operations, the designer must develop a motor which can continue its operation with any of the above fault ar,d severe conditions.

\section{FAULT TOLERANCE DRIVE REQUIREMENTS}

The fault tolerant drive must satisfy the following conditions:

(i) It must be a polyphase drive in which each phase may be regarded as a single module. The operation of one phase must be independent of the others, such that in the event of one phase failure, the others can continue to operate unaffected [3].

(ii) Its enclosure must have high degree of protection especially for motors that operate lat wet and dusty conditions [2].

(iii) Its components must be standard, and commercially available in order to make quick and easy repair [4].

(iv) It must have robust rotor design and high efficiency especially for high speed 'srive applications.

(v) It should have rapid fault detection to enable appropriate post fault action to be taken.

The above modular approach requires that there should be minimal electrical, magnetic, thermal and physical interaction between phases of the drive. Because, without the magnetic isolation, fault currents in one phase induce large voltages in other phases, preventing adequate control of them, and without thermal and physical isolation, the possibility of fault between phases is maximum. Of course the minimal electrical interaction will prevent the fault current transferring from the faulty/ phase to the riealthy phases. 


\section{CONSTRUCTION OF FAULT TOLERANCE DRIVE}

The requirements of fault tolerance drive affect the design of the SRM drive in many aspects. The SRM motor construction can be modified to satisfy the minimum thermal and magnetic interaction, while the drive circuit can be selected to satisfy electrical isolation between phases. These design limitations will be discussed for the motor and its controller separately.

\subsection{Selection of fault tolerance drive circuit}

The choice of drive circuit depends on many factors such as cost, efficiency, energy saving and reliability. To achieve complete electrical isolation between phases, each phase must be supplied from a separate circuit with no sharing of switches between phases. This is naturally true for circuits which use two switches per phase (half bridges). The use of separate half bridges increases the reliability of the system with penalties of more cost and wiring complexity of the circuit [2].

\subsection{Motor construction \\ (i) Normal construction}

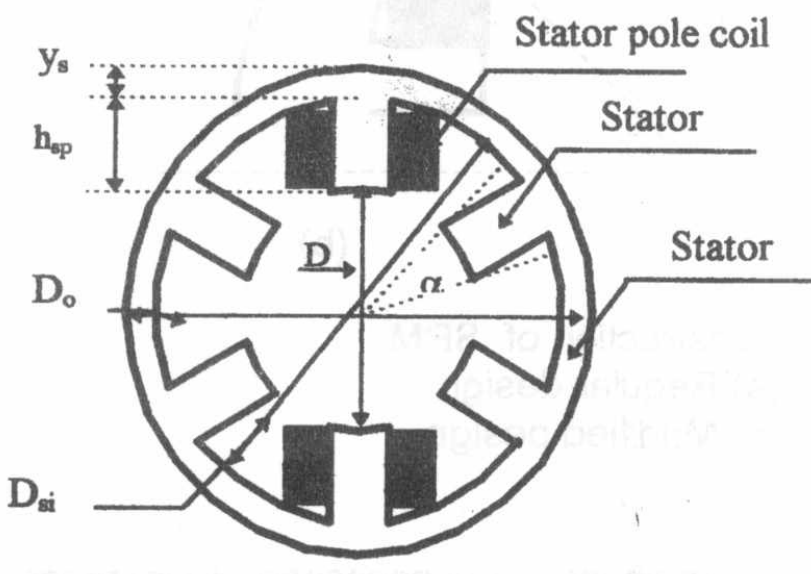

(a)

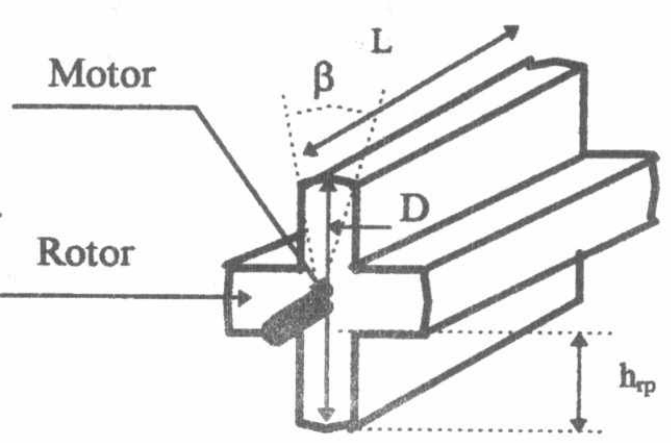

(b)

Figure 1 Motor construction.

(a) Stator dimensions.

(b) Rotor dimensions.

The normal SRM is electromagnetically identical to a single stack variable reluctance stepper motor VRSM as shown in Fig. 1. The rotor has no windings or permanent magnets and the stator poles carry simple coils which are energised by unidirectional current pulses. The opposite pole coils are usually connected in series or parallel to form a phase winding.

The existence of the concentrated coils in the stationary part of the motor is expected to increase the reliability of the insulation system and simplify the rewinding operation when it becomes necessary. Furthermore, the absence of any 
permanent magnets on the rotor will eliminate the thermal limits imposed by the magnetic pole temperature.

The majority of SRMs are totally/ enclosed motors with no cooling mechanisms, because the main losses are generated in the stator which is cooled by natural conduction, radiation and corivection (External self ventilation may be used on some highly-rated motors). This normal cconstruction satisfies small mutual coupling and small thermal inters,ction between phases where the magnetic iron reluctance is negligible and the end windings do not overlap. However, it must be noted that different two phas'e coil sides orcupy the same slot, so that thermal isolation between phases is limited [3].

\section{(ii) Modifie, d construction}

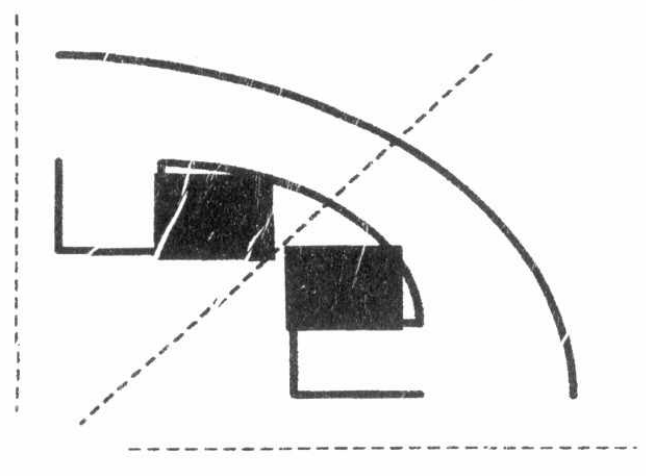

(a)

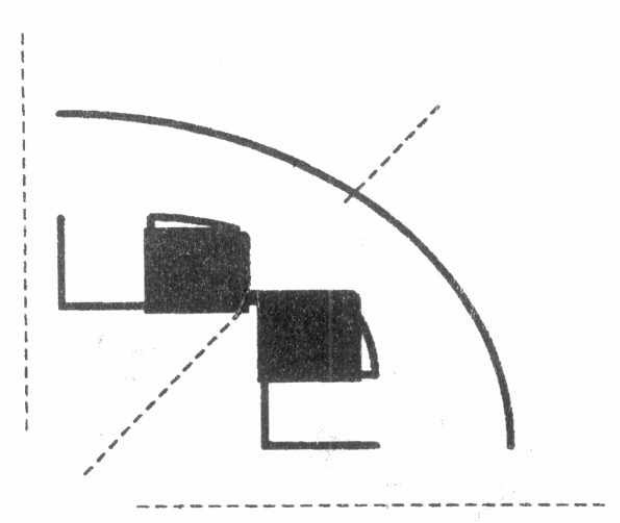

(b)

Fig. 2. Stator construction of SRM.

(a) Regular design.

(b) Modified design.

Because a double phase fault disables two phases, it is necessary to increase the physical and thermal isolation between phases. For well cooled stator frame machines, the dominant temperature rise is within each slot. Therefore, by ensuring that each slot contains one coil side, the thermal and physical interactions between phases are minimised [3]. The effective solution may be done by filling the unused triangular area between the two coil sides of each slot by the lamination itself as shown in Fig. 2.b. This solution also facilitates the fitting coils and increases the thermal contact between the coil and stator steel and hence more output power can be achieved.

Recently, For high speed an'd high efficiency applications, standard silicon steel is replaced by the amorphous iron [5]. The importance of amorphous iron is its ability to limit the stator and ro'tor tooth flux density to about 0.55 Tesla and hence, the torque per unit volume can be improved using the benefit of tooth saturation. The tensile strength of amorphous iron is about three times that of the standard silicon steel a matter that increases the possible maximum speed of the motor. 


\section{MOTOR DESIGN PROCEDURE}

\subsection{Design approach}

In this paper the design is based on magnetic circuit analysis with approximate flux path calculations which provides fast design of many of the SRM dimensions. Also the design is based on the use of standard proportions and graphical relation among motor parts to determine the rest of dimensions.

The static simulation and dynamic performance of the SRM are included as an integral part of the design procedure in order to predict the motor performance and make design verification.

\subsection{Design parameters}

Many parameters are involved in the design of a SRM. As a result, it is necessary to fix some of them and then determine the remaining parameters as part of the design.

\subsubsection{Fixed and quasi-fixed parameters}

Some parameters such as, the number of phases $q$, number of stator poles $\mathrm{m}$, number of rotor poles $n$, lamination stacking factor $k_{s t}$ and conductor resistivity $\rho$ with its temperature coefficient are usually chosen by the designer and assumed as fixed parameters. Other quasi-fixed parameters like, effective current density $\delta$, saturating flux density Bs are assumed constants with the permeability of minor changes in the iterative design method. Usually, some idea about the overall rotor volume and shaft diameter can be estimated from the consumer requirements . Based on this assumption the motor volume and shaft diameter can assumed as quasi-fixed parameters.

\subsubsection{Choice of fixed and quasi-fixed parameters}

\section{(i) Choice of number of stator and rotor poles}

The number of stator poles and rotor poles can be obtained as:

$$
\begin{aligned}
& m=k q \\
& n=m-k
\end{aligned}
$$

Where $k$ is an even number. It has been noted that in order to decrease the iron losses and increase the efficiency, the number of poles must be minimum especially in high speed applications, therefore $k$ is usually taken as 2 to decrease the number of stator poles and hence decrease the number of rotor poles [ 1,6 ].

\section{(ii) Choice of number of phases}

The fault tolerant motor must be a polyphase mator, and hence all single phase motors are rejected. For constant power operation, it may be wanted to make the drive continue to produce its full load power under one phase failure fault condition. From this point of view, a fault tolerant over rating factor will defined as:

$$
K_{0,}=q /(q-1)
$$

Where $q$ is the number of phases.

If there are four phases at healthy conditions then, if one phase is faulted, the others must be overrated by $33 \%$ in order to give full load capacity [2]. It is clear 
that the value of $\mathrm{K}_{\mathrm{or}}$ is decreased with the increase of the number of phases. However, on the debt side, more leads have to be brought out from the motor, more connections are needed. In practice the majority of motors have three or four phases, and it is rare to find motors with more than six phases.

From reversible self-starting and small torque ripples point of view, there must be adequate an overlap between the similar inductance variations of adjacent phases. Thus, all single and two-phase motors are rejected from this point of view.

From efficiency point of view, the number of phases must be kept as low as possible to decrease the switching frequency and hence decrease the iron losses which may be the dominant loss in high speed operations. From this point of view three phase motors are the best choice for high speed, fault tolerant drives.

However, if a low speed application is being considered, the limitation imposed by frequency will be less effective and the designer has greater freedom in choice.

(iii) Choice of magnetic loading

The magnetic flux density $B$ is relevant to the electromechanical power conversion process and basically, it is determined by, the maximum saturating flux density in the iron parts of the machine, the iron losses and the magnetising current.

The maximum flux density in any part of the magnetic circuit must be less than the limiting saturation value of the used magnetic material. In a well designed regular SRMs the maximum flux density occurs in the stator poles and it ranges from 1.8 to 2.5 Tesla depending on the used material [7].

New low-loss amorphous laminated structure of $0.03 \mathrm{~mm}$ thickness operated at 0.55 Tesla flux density offer great promise in the design of SRMs, especially for high speed applications [5].

\section{(iv) Choice of current density}

The value of working current density $\delta$ depends on the cooling methods employed in the motor. This value normally ranges from 4 to $10 \mathrm{~A} / \mathrm{mm}^{2}$ for non-aerospace applications and from 10 to $20 \mathrm{~A} / \mathrm{mm}^{2}$ for aerospace applications [8].

\section{(v) Estimation of rotor volume}

The output of a machine can be related to its rotor volume and speed by an equation usually known as the output equation. In terms of power, the simplest form of this equation is

$$
P=C_{0} V_{R} n_{r}
$$

Where $C_{0}$ is the output coefficient, $V_{R}$ is the rotor volume and $n_{r}$ is the base speed. It is easy to determine $C_{0}$ for an existing motor whose power, speed and rotor dimensions are known. For similar cooling, this value can be used as a starting point for a new design of the SRM of the same power and speed $[9,10]$.

\section{(vi) Estimation of shaft diameter}

The shaft of a SRM is short and stiff to maintain the necessary small airgap. The use of ball and roller bearings makes accurate centring of the rotor readily possible. For high torque and high-speed applications, the increase of the shaft stiffness may be done by [11]:

1- placing the rotor laminations under heavy pre-compressed construction so that the stack contributes the overall thickness of the shaft.

2- placing the bearings as closely as possible to the rotor stack.

3- using the largest possible shaft diameter permitted by the electromagnetic design of the rotor core. 
Although, the shaft is not only designed from consideration of pure torsion, the conventional formula is usually based upon such consideration. For a solid shaft diameter $d_{s h}$, the usually used expression is:

$$
d_{s h}=c \cdot \sqrt[3]{\frac{P}{n_{r}}} \quad \mathrm{~cm}
$$

Where, $P$ is the output power in $K W, c$ is constant and $n_{r}$ is the rotor speed in r:p:m.

\subsubsection{Geometrical and relational parameters}

Many parameters such as the outer stator diameter $D_{0}$, and airgap length $I_{g}$, the stator and rotor pole widths $t_{s}, t_{r}$, and the stator and rotor yoke widths $y_{s}, y_{r}$ e.t.c. can be computed from the fixed and quasi-fixed parameters geometrically or by 'ratioing' from the main dimensions, starting from 'standard' proportions. The standard proportions include the motor aspect ratio $A R$ and the motor split ratio $\mathrm{sr}$

\subsubsection{Estimation of relational parameters}

\section{(i) Estimation of main dimensions}

The factors which influence the relative values of main dimensions $D$ and $L$ are different for different types of electric machines. For SRM these factors include:

-The ratio $A R$, of core length $L$ to the stator pole pitch $\tau_{s}$ which determines the weight of the copper and hence the economics of the machine as:

$$
\frac{L}{D}=A R_{1} \cdot \frac{\pi}{m}
$$

For $A R_{1}$ ranges from 1 to 6 and $m$ ranging from 6 to 12 , the value of $L D$ ranges from 0.3 to 3 .

-The rotor critical speed imposes a limit on the rotor diameter $D$, because if the rotor peripheral speed $V_{p}$ is increased, the rotor may be destroyed due to increased centrifugal force. The peripheral speed may be greater than $175 \mathrm{~m} / \mathrm{s}$ for high speed SRMs incorporating amorphous iron [5]. However, the peripheral speed usually does not exceed $60 \mathrm{~m} / \mathrm{s}$ for most normal SRMs.

\section{(ii) Estimation of envelope dimensions}

The envelope dimensions are the stator outer diameter $D_{0}$ and the envelope axial length $L_{0}$ measured over the end-turn overhang. In aerospace application, the envelope volume is one of the consumer requirements and in this case the designer must satisfy this restriction in his design.

When the envelope dimensions are not specified, it is easy to estimate them by standard scaling from the main dimensions. The simplest way to estimate the outer stator diameter $D_{0}$ is from a typical or
standard split ratio sr, which is defined as:

$$
s r=\frac{D_{S}}{D_{o}}
$$

This ratio may vary over quite a wide range between 0.4 to 0.7 , with most designs around 0.5 to 0.57 depending on the number of stator and rotor poles, and on the operating requirements [12].

The envelope length Le may be estimated as the stack length plus two end turn overhangs. The maximum overhang length or the coil thickness can be approximated as 0.5 of the inner stator interpolar arc. If the interpolar arc is equal to 
0.5 of the stator pole pitch. Then, the overhang length is approximately equal to 0.25 of the stator pole pitch. The envelope length can be expressed as:

$$
L_{e} \cong L+\frac{\tau_{s}}{2}
$$

(iii) Estimation of airgap length

For induction motor, which has cylindrical rotor with short airgap length, the constant $c$ in equation (5) is usually taken as 25. For SRM, the weight of the salient rotor structure is often less than that of the induction motor, and so, the constant c may be taken as fraction of 25 , but for high speed and for safety it is useful to take it as that of induction motor.

Also, the airgap may be increased to decrease the unbalance magnetic pull, which arises from any small deflection or eccentricity of the rotor shaft especially at high speed operations.

For high power and high speed applications the following relation may be proposed based on the relation of the airgap length of induction motor and may also be usefully used for SRD [2]:

$$
l_{g}=0.2+D \quad \mathrm{~mm}
$$

Where, $D$ is the bore measured in meter.

This relation permits relatively larger airgap length and hence more safe and quiet high speed operation, but with the penalty of lower specific torque.

\section{(iv) Estimation of stator pole dimensions}

The stator pole arc $\alpha$ and the corresponding tooth width $t_{s}$ requires careful selection to satisfy the following conditions:

1-The stator pole arc must be greater or equal to the step angle to ensure adequate overlap between phases and hence ensure self-starting at all rotor positions.

2-The stator pole arc must be less than the rotor interpolar $\operatorname{arc} \beta^{\prime}$ to ensure angular clearance between the stator and rotor pole corners and hence ensure sufficiently low unaligned inductance $L_{u}[1,8]$.

Once the stator pole arc has been chosen, the stator pole width can be determined from the following relation:

$$
t_{s}=\pi D_{s} \frac{\alpha}{360}
$$

The optimum range for the stator pole arc to stator pole pitch, changes according to the objective function. However, in order to optimize the motor performance generally the optimum value can be taken between 0.33 and 0.42 [12]. Stator yoke width $y_{s}$ is a magnetic relational parameter. So, it can be determined by the solution of the magnetic circuit. Where the stator pole flux splits equally in both the stator and rotor back irons, thus the back iron width must support one half of the stator pole flux. If the maximum flux density allowed in the back iron is $B_{\max }$, then the back iron width can be computed as:

$$
y_{s}=\frac{\phi_{s}}{2 B_{\max } k_{s t} L}
$$

Where, $k_{s t}$ is the lamination stacking factor. 
Where the stator yoke represents the longest path for the magnetic flux. So to decrease saturation and hence decrease iron losses, we will take the stator back width as 0.55 to 0.75 of the stator pole width $t_{s}[6,8,12]$.

\section{(v) Estimation of rotor pole dimensions}

The rotor pole arc $\beta$ and the corresponding tooth width $t_{r}$ require careful selection to satisfy the following conditions:

1- As shown in the stator pole arc, the rotor pole arc must be greater or equal to the step angle to ensure self starting of the motor at all rotor positions.

2- The rotor pole arc is preferred to be greater than the stator pole arc, this results in a region of constant inductance separating the positive and negative $\mathrm{d} L / \mathrm{d} \theta$ regions, which in turn provides additional time for the phase current to be completely turned off before the region of negative torque production, i.e.

$$
\beta \geq \alpha
$$

In terms of widths, $t_{r}$ should be greater than $t_{s}$ by about $2 \mathrm{I}_{g}$ and the rotor pole width can be computed as:

$$
t_{r}=\pi D \frac{\beta}{360}
$$

The rotor yoke width $y_{r}$ is a magnetic relational parameter. So, it can be determined by the solution of the magnetic circuit, where the rotor pole flux splits equally in both the rotor back irons. Thus the yoke iron width must support one half of the pole flux. Usually the rotor yoke width is chosen to equalize flux density in the rotor pole iron and in the rotor yoke iron. This leads to:

$$
y_{r}=\frac{t_{r}}{2}
$$

The rotor pole height $h_{r p}$ is a geometrical parameter which can be computed for the trapezoidal pole with a rectangular slot shape as:

$$
h_{r p}=0.5\left(D-D_{r i}\right)
$$

where, $D_{r i}$ is the internal rotor diameter, $D$ is the external (outer) rotor diameter.

\section{DESIGN OF STATOR WINDING}

In SRM, there are two types of coils:

(i) Dropped in coils, which are wound and insulated before being dropped into the slots. The slots thus have wide openings and in this type of coils the maximum slot filling factor is about 0.4 .

(ii) Pushed through coils, in which individual conductors of the coil are introduced one by one into the slot, thus narrow slot openings can be used. The slot filling factor may be as low as 0.4 for small round conductors increasing to 0.65 for large round conductors and to 0.75 for rectangular conductors.

\subsection{Number of turns}

In this design approach, the design point is taken to produce the flat topped current waveform at minimum speed at which the full power is produced. According to this approach the back emf $E$ is equal to the dc bus voltage $V$, the back emf $E$ can be expressed as: 


$$
E=\omega \frac{\lambda_{\max }-\lambda_{\min }}{\alpha}
$$

where $\lambda_{\max }$ is the maximurr, aligned flux linkage and $\lambda_{\min }$ is the minimum or the unaligned flux linkage for the peak phase current and $\omega$ is the angular velocity (rad./s).

$$
\begin{aligned}
& \lambda_{\text {max }}=0.5 \gamma_{P H}\left(B_{S} \cdot k_{S T} \cdot L \cdot D \cdot \alpha\right) \\
& \lambda_{\min }=k \lambda_{\max }
\end{aligned}
$$

From equations (16), (17) and (18) the number of turns per phase can be estimated as:

$$
N_{P H}=\frac{60 \mathrm{~V}}{(1-k) \cdot K_{S T .} \pi n D L B_{S}}
$$

The value of $k$ depends on the degree of saturation and ranges from less 0.1 for small-unsa.،urated machines to about 0.5 or more for heavy saturated machines.

\section{$6.2 \mathrm{Cr}$, nductor area}

The conductor area can be computed by assuming a maximum value of slot filling factor $k_{f}$ for two coil side per slot, and a suitable value of effective current density $\delta$ then the conductor area can be computed as:

$$
a_{w}=\frac{I_{R \cdot M S}}{\delta}
$$

'Where, $I_{\text {R.M.S }}$ is the effective currerit per phase and $\delta$ is the effective current density which ranges from 3 to 6 for totally enclosed natural cooling motors and from 7 to 10 for external self ventilation motor:s [8].

The effective phase current can be approximated for ideal square current pulse of conduction angle equals $(1 / / 4)$ of the cyclic period as $[13,14]$ :

$$
I_{\text {R.M.S }}=\frac{\operatorname{Im}}{\sqrt{q}}
$$

Where, Im is the, maximum flat current which can be computed from Ampere's circuital law at alis,jned position.

The conductor area must make the total copper area per slot satisfies a filling factor less or equal to the maximum filling factor.

\section{SIMI'LATION RESULTS AND MOTOR DESIGN}

For $16 \mathrm{KW}, 270 \mathrm{~V}, 4$-phase, $13000 \mathrm{rpm}$, air cooled SRM. The main results of the dessign and simulation are explained in table 1. 
Table. 1 Main parameters of the SRM design

\begin{tabular}{|l|c|l|c|}
\hline \multicolumn{1}{|c|}{ Main parameters } & $\begin{array}{c}\text { Normal } \\
\text { design }\end{array}$ & \multicolumn{1}{|c|}{ Main parameters } & $\begin{array}{c}\text { Normal } \\
\text { design }\end{array}$ \\
\hline Number of stator poles & 8 & The outer volume $\left(\mathrm{V}_{\text {out }}\right)$ & $0.0014 \mathrm{~m}^{3}$ \\
\hline Number of rotor poles & 6 & Maximum phase inductance $\mathrm{L}_{\text {max }}$ & $5.775 \mathrm{mH}$ \\
\hline Rotor diameter $(\mathrm{D})$ & $0.075 \mathrm{~m}$ & Minimum phase inductance $\mathrm{L}_{\min }$ & $0.378 \mathrm{mH}$ \\
\hline Axial stack length $(\mathrm{L})$ & $0.114 \mathrm{~m}$ & Maximum phase current $\mathrm{I}_{\mathrm{m}}$ & $103.735 \mathrm{~A}$ \\
\hline Internal rotor diameter $\left(\mathrm{D}_{\mathrm{ri}}\right)$ & $0.046 \mathrm{~m}$ & Maximum flux density $\mathrm{B}_{\mathrm{s}}$ & $1.951 \mathrm{Tesla}$ \\
\hline Airgap length $(\mathrm{lg})$ & $0.2 \mathrm{~mm}$ & No load saliency ratio & 15.277 \\
\hline Stator diameter $\left(\mathrm{D}_{\mathrm{s}}\right)$ & $0.076 \mathrm{~m}$ & Switching frequency & $5200 \mathrm{~Hz}$ \\
\hline Stator intemal diameter $\left(\mathrm{D}_{\mathrm{si}}\right)$ & $0.106 \mathrm{~m}$ & \multicolumn{1}{|c|}{ Mechanical losses } & $0.146 \mathrm{KW}$ \\
\hline Outer diameter $\left(\mathrm{D}_{\mathrm{o}}\right)$ & $0.12 \mathrm{~m}$ & Motor full load efficiency $\eta \%$ & $80.26 \%$ \\
\hline Number of turns per phase & 34 & Cooling fan power $P_{\text {tan }}$ & $0.153 \mathrm{KW}$ \\
\hline Shaft diameter $\left(\mathrm{d}_{\mathrm{sh}}\right)$ & $0.027 \mathrm{~m}$ & Type of magnetic material & $\mathrm{g} 203$ \\
\hline
\end{tabular}

Figures 1-4 show the per-phase steady state current, linear inductance, static and dynamic magnetization curves, and coenergy curves. Figures 5,6 show the dynamic, average and resultant torque curves. From these figures, it is clear that the average torque is about $15 \mathrm{Nm}$ which gives an overall torque density of $10345 \mathrm{Nm} / \mathrm{m}^{3}$, which can be increased by increasing the specific magnetic and electric loads (according to the type of magnetic material and method of cooling) [7].

By using $\mathrm{CoFe}$ magnetic material, the maximum flux density can be increased to about 2.5 Tesla. This increase in the maximum flux density will decrease the rotor volume by a factor approximately equal to $\left((1.951 / 2.5)^{2}=0.6\right)$ and increase the torque density to about $17241 \mathrm{Nm} / \mathrm{m}^{3}$. The previous decrease in the overall volume requires larger current density with liquid cooling method.

Miller [8] defines the peak KVA rating of a power converter as the product of the number of switches, the DC link voltage and the maximum phase current. From this point of view, the overall peak KVA of the motor drive is about $224 \mathrm{KVA}$ This implies that the power converter requirement is about $14 \mathrm{KVANK}$ which lies in the range of PM and SR machines. 


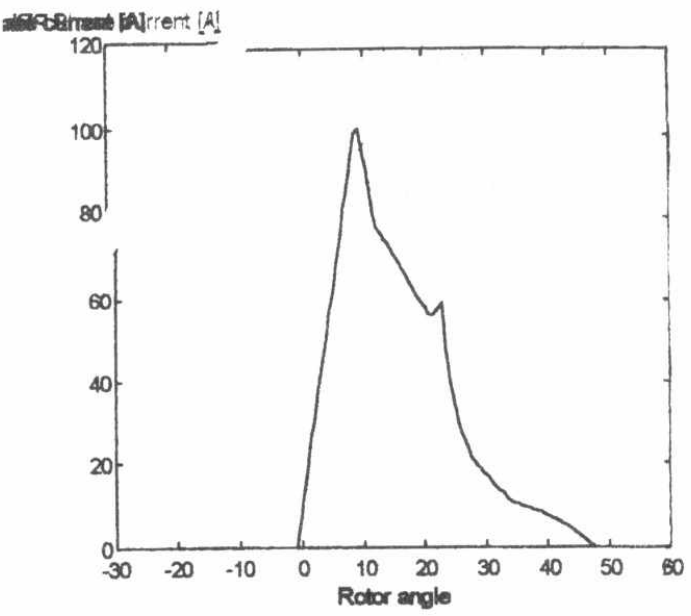

Fig. 1 Steady state per-phase current

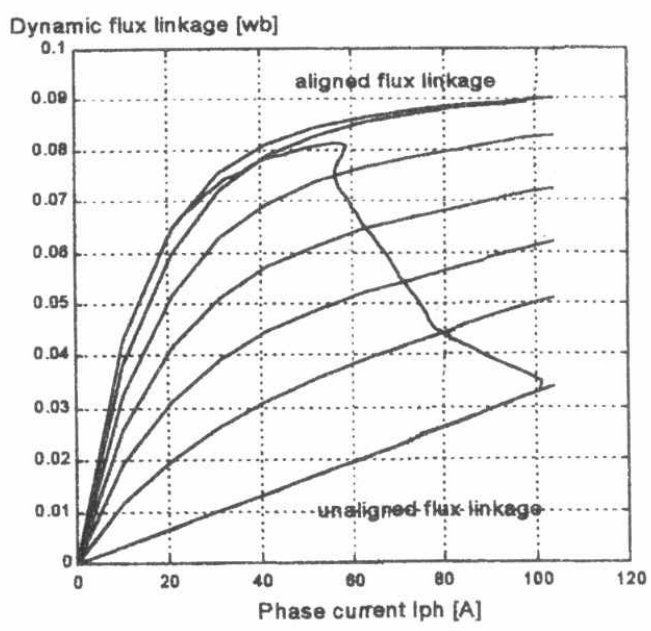

Fig.3 Dynamic magnetization curves

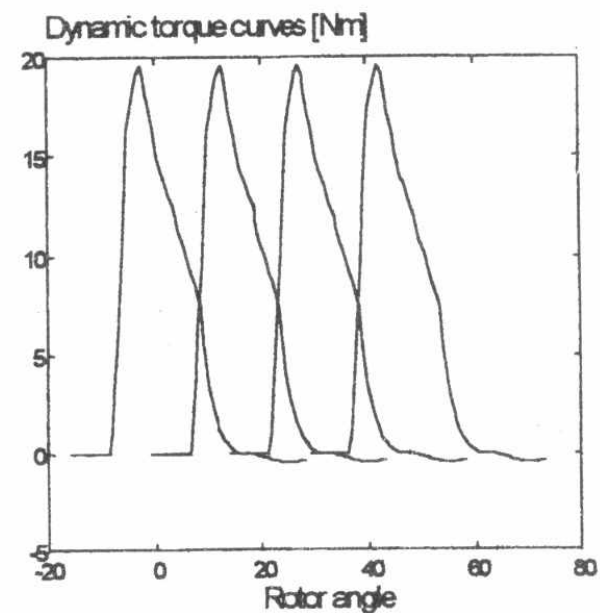

Fig.5 Dynamic Full load torque curves

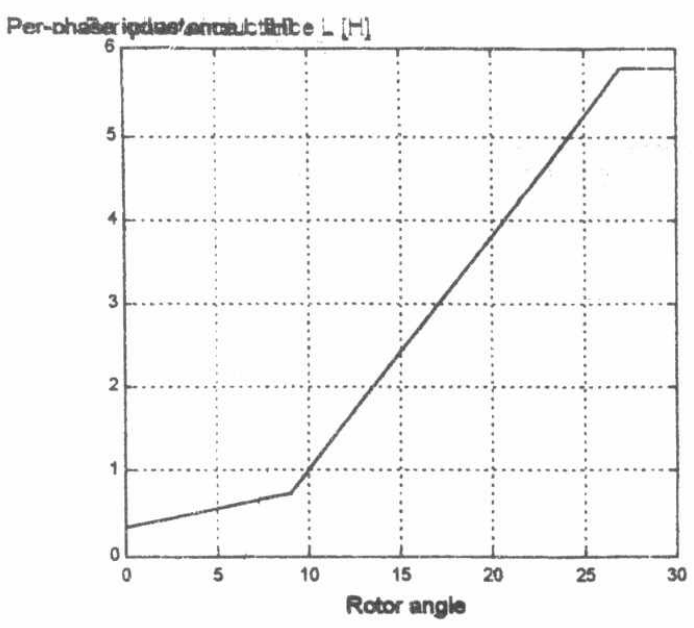

Fig.2 Per-phase inductance

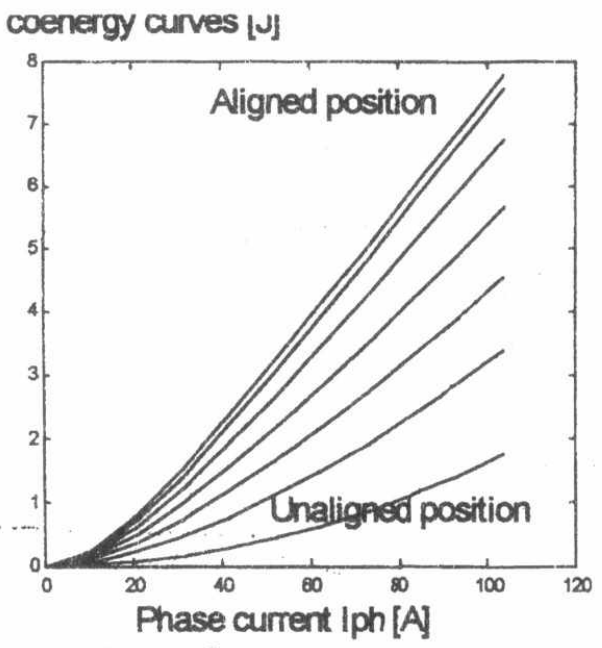

Fig. 4 Coenergy curves

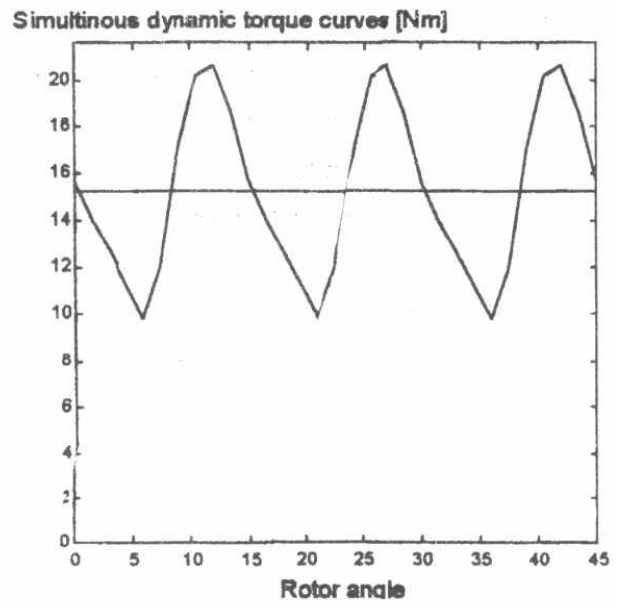

Fig.6 Resultant and Average Torques 


\section{CONCLUSION}

The paper introduces a systematic design procedure of SRMs in a manner which is very similar to that used for the traditional machines. This design approach combines among magnetic, graphical and relational parameters, in order to estimate the whole motor dimensions. Since, the geometrical parameters and the resulting change in the magnetic flux distribution are related analytically, it is very simple to obtain a basic insight into the effect of various parameters on the magnetic field distribution without need of many finite element analysis solutions.

Finally, the proposed routine is applied to design a $16 \mathrm{KW}, 13000$-rpm fault tolerant drive, which can be used in aircraft applications. The simulation results confirm that the system is capable of meeting the required performance indices such as the rated torque, speed, efficiency and KVA rating of the power converter.

\section{REFERENCES}

[1] P. J. Lawrenson, J. M. Stephenson, J. Corda, and N.N. Fulton, "Variable Speed Switched Reluctance Motors", IEE Proc., Vol. 127, Pt. B, No. 4, pp. 253 -265 , July (1980).

[2] M. A. L. Badr, R. Mostafa, and Amged S. El-wakeel, " Switched reluctance Drive As Fault Tolerant Drive ", Proceeding of the 1st ICEENG conference, M.T.C., Egypt, 24 - 26 March, (1998).

[3] B. C. Mecrow, A.G. Jack, J. A. Haylock, and J. Coles, " Fault Tolerant Permanent Magnet Machine drives", IEE Proc., Vol. 143, No. 6, pp. 437 - 442 , November (1996).

[4] M. I. Kamel, "Design and Implementation of Fault- Tolerant Controller System", ICECS' 97, Cairo, Egypt, pp. 984 - 991, (1997).

[5] K. Backhaus, L. Link, and J. Reinert, "Investigation on a High Speed SRD incorporating Amorphous iron", EPE 95, Sevilla, pp. 460 - 464, (1995).

[6] M. M. Ahmed and M. A. EL-Khazendar, " Optimum Design of an Isolated Switched Reluctance Generator", AL-Azhar Engineering Fourth International Conference, pp. 330 - 341, December 16 - 19, (1995).

[7] Arther V. Radun, "Design Consideration for the Switched Reluctance Motor", IEEE Trans. on Ind. Appl. , Vol. IA-31, No. 5, pp. $1079-1087$, September I October (1995).

[8] T. J. E. Miller, Switched Reluctance Motors and Their Control. Published jointly by Hillsboro, OH: Magna Physics Tridelta and London, UK: Oxford University Press, (1993).

[9] Austin hughes, Electric Motors and Drives: Fundamentals, Types and Applications, second edition, Newness, (1994).

[10] T. J. E. Miller and M. McGilp, " PC CAD for Switched Reluctance Drives ", Electric Machines and Drives Conference, London, UK., IEE Conference Publication 282, pp. 360 - 366, December (1987).

[11] Caio A. F., Stephen R. J., William S. H., and William D. J., "Detailed Design of a 30-KW Switched Reluctance Starter/Generator System for a Gas Turbine Engine Application". IEEE Trans. on Industry Applications, Vol. 31, No. 3, pp. 553-561, May/June (1995). 
[12] J. Faiz, and J. W. Finch, "Aspects of Design Optimization For Switched Reluctance Motors", IEEE Trans. on Energy Conversion, Vol. EC,-8, No. 4, pp. 704 - 713 , December (1993).

[13] J. R. Suriano, and Chee-Mun Ong, "Variable Reluctance Motor Structures For Low Speed Operation", IEEEE Trans. on Ind. Appl. , Vol. IA-32, No. 2, pp. 345 353 , March / April (1996).

[14] R. Krishrian, R. Arurnugam, and J. F. Lindsay, "Design procedure for Switched Reluctance, Motor", IEEE Trans. on Ind. App., Vol. IA-24, No. 3, pp. 456 - 461, May / Jisne (1988). 